\title{
ESPAÇOS DE LEITURAS NAS INSTITUIÇÕES EDUCACIONAIS: REFLEXÕES SOBRE O LEITOR REAL E VIRTUAL
}

\section{Marouva Fallgatter Faqueti \\ Ursula Blattmann}

\section{Resumo:}

Apresenta a importância de proporcionar qualidade ambiental do espaço físico real e no ambiente virtual destinado à leitura e produção de conhecimento em bibliotecas envolvidas na estrutura educacional (em instituições de ensino e centros de pesquisa). As bibliotecas tornam-se um diferencial positivo no processo de aprendizagem. Ao bibliotecário são necessárias habilidades e competências dinâmicas em promover e administrar espaços para interação dos leitores com o mundo da leitura. Facilitar um ambiente adequado para os estudos, encontros intelectuais, debates com autores e discussões de leituras são primordiais para o transmitir, gerar e inovar conhecimentos nas diferentes áreas do saber. Entender as transições do leitor de páginas ao indivíduo que interage pelo vídeo: o leitor de telas na teia global. São abordadas questões de como e por que transformar os espaços de acesso e uso de fontes de informação capazes de proporcionarem inúmeras leituras a ser realizadas entre os mundos das imagens, palavras, hipertextos e hipermídia. Algumas considerações sobre os impactos da divisão digital e o acesso e uso de fontes de informação para o desenvolvimento e construção da Sociedade do Conhecimento.

\section{Palavras-chave:}

Bibliotecas; Leitura; Espaço de leitura; Acesso à informação; Divisão digital; Letramento.

\section{READING SPACES IN EDUCATIONAL INSTITUTIONS: REFLECTIONS ABOUT THE REAL AND VIRTUAL READER}

\begin{abstract}
:
It presents the importance to provide a quality environment to the physical and virtual space intented to reading and to knowledge production at educational libraries (educational institutions and research centers). The libraries become a positive differential at the learning process. To the librarians some dynamic competences and abilities are necessary to promote and manage interaction spaces to readers at the reading world. How to facilitate an environment for the intellectual studies, meetings, debates with authors and readings exchange experiences, is primordial to transmit, to generate and to do knowledge innovation at different areas of knowledge. Understand the transitions between the books reader (paper) to the person that interacts in the video: the screen reader in the world wide web. Some questions about how and why librarians have to build up spaces to access and use information resources to provide information literacy in the worlds of images, words, hipertexts and hipermídias. Digital division impacts, access and use of information resources have to be considerated to the development and construction of the Knowledge Society.
\end{abstract}

Keywords:

Libraries; Reading; Reading space; Information access; Digital division; Information literacy. 


\section{INTRODUÇÃO}

Bibliotecas em ambientes educacionais necessitam atentar para o zelo aos espaços e ações destinados à leitura e à produção de conhecimento.

Saber cuidar, dentro de uma perspectiva descrita por Leonardo Boff (1999), pode ser o diferencial positivo a ser estimulado entre os bibliotecários, no sentido de humanizar os espaços e as relações tecidas em ambientes reais e virtuais.

Cuidar do espaço físico envolve conhecimento das dificuldades e necessidades dos usuários no uso da biblioteca, criatividade para idealizar novos projetos, empreendedorismo para implantá-los, integração com diversos segmentos da instituição na qual se está inserido afim de não perder de vista o objetivo maior que é a satisfação das necessidades dos leitores.

Quando se reporta para as dificuldades e necessidades dos usuários, são percebidas lacunas na interação simultânea do acesso às fontes de informação impressa, digital e virtual. Freqüentemente os espaços coletivos e individuais na biblioteca são organizados de maneira setorial, por exemplo: sala de acesso ao acervo, sala de acesso a Internet (com mesas individuais e sem espaço para livros), obras raras, entre outros.

Partindo de uma visão mais holística e processual, a criatividade é um elemento essencial na administração dinâmica de bibliotecas. É através dela que o bibliotecário poderá transpor o modelo tradicional de gerenciamento do espaço físico local para uma dimensão capaz de dar conta de responder corretamente às necessidades do usuário e ou dar oportunidade para melhor ocupação do espaço no ambiente educativo.

A capacidade empreendedora e pró-ativa são competências e atitudes fundamentais ao bibliotecário na construção de novos ambientes. A biblioteca não é um quadrado isolado, nesse espaço precisam acontecer as interações do sujeito leitor e também considerar que existem interferências e pressões externas e internas constantemente. 
Quando se vislumbra algumas mudanças na estrutura formal de funcionamento é importante ter clareza das necessidades - certamente haverá concordâncias e resistências presentes no contexto, de forma explícita ou não. $\mathrm{O}$ diálogo, o respeito, a persistência e capacidade argumentativa na busca de uma solução mais adequada são valores que devem permear o processo administrativo nos ambientes educacionais. As bibliotecas são consideradas espaços educativos e colaboram positivamente no processo de aprendizagem do indivíduo.

A ampliação das maneiras sócio-interacionais, isto é, na relação de interação leitor - fontes de informação; leitor - leitor; leitor - bibliotecário e bibliotecário - comunidade significa um espaço de muitas relações entre os atores desse processo.

A comunicação formal e informal ocorre constantemente. É necessário que se estabeleça um campo para a ação de espaços dinâmicos, pois a transmissão e principalmente a produção de conhecimento envolve movimentos não explicitados pelas pessoas. Cabe ao profissional conhecer os processos de leitura e letramento para identificar o que cada leitor demanda, entender também as necessidades não verbalizadas e ofertar produtos e serviços relevantes, posto que, muitas vezes ele não possui ampla visão de outras possibilidades que no momento ele desconhece e só um(a) bibliotecário(a) pode diagnosticar as lacunas e apresentar serviços adequados.

\section{LEITURA, ALFABETIZAÇÃO E LETRAMENTO}

A leitura e a escrita são habilidades que auxiliam positivamente no processo de aprendizagem das pessoas. Nas escolas os processos de leitura e escrita são ensinados paralelamente, mas são distintos e merecem especial atenção dos educadores (professores e bibliotecários) preocupados na qualidade da educação, na melhoria do acesso e do uso da informação e acima de tudo em possibilitar o exercício pleno da cidadania.

O retrato da leitura de determinada sociedade é importante para fornecer informações ao planejamento de políticas públicas nas áreas de desenvolvimento social, econômico, 
industrial. Não basta ensinar a leitura e a escrita - alfabetizar, é preciso oferecer condições mínimas ideais de acesso à informação registrada em suportes como o papel e o digital. Isso quer dizer que as escolas ensinam a ler e a escrever, mas faltam instrumentos de apoio básico (material informativo, de lazer, de pesquisa) para dar continuidade a estas habilidades na promoção do ser humano.

O letramento, essa continuidade da leitura e da escrita, precisa existir em todos os espaços educativos e culturais. Urge a necessidade de mais e melhores bibliotecas, seja nas escolas ou nas cidades, para prover o acesso à informação as pessoas.

\subsection{Habilidades e atividades na educação}

O bibliotecário desenvolve atividades importantes no apoio do processo de aprendizagem. Precisa saber organizar espaços de acesso e estimular o uso da informação seja esta visual, auditiva, não-verbal, textual, hipermídia. Promover espaços dinâmicos e interativos e atividades para poder sobreviver na Era do Conhecimento, no qual o acesso e uso da informação nas dimensões de tempo, espaço e velocidade é o diferencial. O saber localizar com precisão a informação desejada, saber diferenciar o joio do trigo, zapear a informação no contexto de bibliotecas e na internet, conforme salientado por Blattmann e Fragoso (2003) possibilita sobreviver numa sociedade em constantes e profundas mudanças.

Cada vez mais numa sociedade que se diz na Era do Conhecimento, o bibliotecário precisa conhecer e principalmente compreender as relações existentes entre a técnica, a teoria, a prática e as relações de poder que estão nas entranhas dos processos, nas relações subjetivas. Cabe lembrar que tudo se transforma, tudo está relacionado a determinado contexto, sofre pressões e apresenta resultados, muitas vezes inadequados ao desenvolvimento do ser humano mas que satisfaz aos donos da manipulação de massas.

O bibliotecário mergulha também nesse mundo digital on-line para compreender a importância dos recursos técnicos e operacionais, como: entender sobre a compilação de softwares e tutoriais que auxiliam no aprendizado dos equipamentos, dos aplicativos e 
principalmente em saber criar - gerar conhecimentos. Isso significa que precisa saber como interagir em vídeo-aulas, em preparar o ambiente para uma teleconferência, em desenvolver conteúdos a serem utilizados pelos sujeitos de seu ambiente de informação, identificar quais as melhores ferramentas para tratamento de edição e criação de arquivos de textos, imagens, sons e vídeos.

Além das preocupações de estimular ações leitoras do leitor real, preocupa-se com o leitor do virtual. Muitas perguntas são direcionadas para desenvolver competências, habilidades e atitudes no manuseio da informação registrada em arquivos digitais, em bases de dados, nos sites, em portais, nas conferências eletrônicas, em listas e grupos de discussão, em estabelecer conexões eletrônicas para a recepção e transmissão de dados e informações.

O perfil do bibliotecário conforme a descrição sumária descrita na Classificação Brasileira de Ocupações - CBO, edição 2002 (http://www.mtecbo.gov.br/busca/descricao.asp?codigo=2612 ) :

Disponibilizam informação em qualquer suporte; gerenciam unidades como bibliotecas, centros de documentação, centros de informação e correlatos, além de redes e sistemas de informação. Tratam tecnicamente e desenvolvem recursos informacionais; disseminam informação com o objetivo de facilitar o acesso e geração do conhecimento; desenvolvem estudos e pesquisas; realizam difusão cultural; desenvolvem ações educativas. Podem prestar serviços de assessoria e consultoria.

Certamente a técnica está entrelaçada com a desenvoltura da ação real e não apenas de discursos lindos que na prática não acontecem. Na organização e administração da informação no espaço digital, é necessário considerar aspectos dos diferentes públicos, como apresentam Sales e Cybis (2003), para que realmente aconteça o acesso e uso da informação.

Além da estrutura mínima desejável, é pertinente incorporar ao contexto as novas práticas sem mistificar ou criar fobias no manuseio da tecnologia. Cabe pautar-se em princípios éticos em todas esferas sociais, pessoais e organizacionais para que seja possível persistir a serenidade, a prudência, a autoridade. Enfim o perfil de determinado profissional é como 
uma jóia rara: lapidado aos poucos, aplicando técnicas, métodos, instrumentos, muita leitura e reflexão pautada na prática.

\subsection{Educação para minimizar a divisão digital}

A educação familiar e escolar, bem como a sociedade, exercem um papel preponderante na formação de um conjunto de crenças e valores individuais e coletivos que norteiam o uso das informações que as pessoas fazem ao longo de suas vidas. Esse processo de construção complexo de conhecimentos ocorre num contínuo fazer e refazer multidimensional envolvendo componentes mentais, psicológicos, sociais, econômicos, políticos e culturais.

A educação formal exerce papel fundamental neste contexto posto que se propõe a utilizar diversos meios que permitam "[...] assegurar a formação e o desenvolvimento do ser humano" (MORIN, 2000, p. 10). Vale aqui ressaltar que esse "desenvolvimento" deve ser entendido "[...] como a evolução da capacidade de raciocinar e imaginar, da capacidade de discernir, do sentido das responsabilidades”, segundo Relatório para UNESCO elaborado pela Comissão Internacional sobre Educação para o século XXI (DELORS et al, 2000, p. 9).

Uma utopia educacional para o século XXI é o fortalecimento de uma sociedade educativa, isto é, educação contínua ao longo da vida. Delineia-se em resposta ao desafio de uma realidade em mudança, onde aprender a aprender deverá ser o cotidiano de todos. Configura-se então como funções relevantes do processo educativo "[...] a aquisição, atualização e utilização dos conhecimentos”. Portanto, “[...] a educação deve permitir que todos possam recolher, selecionar, ordenar, gerir e utilizar as mesmas informações" (DELORS et al, p. 21).

Fica aqui explícita a preocupação da Comissão com relação à preservação da igualdade de condições de acesso a dados e fatos para todos, bem como, as habilidades a serem desenvolvidas para seu uso. Ratifica-se que não basta proporcionar o acesso, mas é importante promover o chamado "letramento informacional" conhecido como "information literacy". 
McGarry (1994) definiu cinco estágios de armazenamento e transmissão de informação na sociedade: estágio oral; estágio do alfabeto; estágio do manuscrito; estágio da impressão e estágio eletrônico. Esses estágios co-existem harmonicamente de forma não linear. Para cada nível as pessoas requerem conhecimentos e habilidades específicas para fazer o uso significativo das informações transmitidas. A alfabetização ideal é aquela que desenvolve habilidades de pensar criticamente e buscar significados em suas próprias vidas e na vida de outros.

O letramento no uso da informação é a base para o aprendizado ao longo de toda a vida. Ele é comum para toda as disciplinas, para todos os ambientes de aprendizagem e para todos os níveis de educação. Ele capacita aprendizes para aprender através das informações e estender suas investigações assumindo o controle sobre sua própria aprendizagem.

A Association of College and Research Libraries considera que um indivíduo letrado no uso da informação é capaz de: a) determinar a extensão da informação que necessita; b) acessar a informação eficaz e eficientemente; c) avaliar as informações e suas fontes criticamente; d) incorporar as informações selecionadas como seu conhecimento; e) usar a informação efetivamente para realizar propostas específicas; f) entender o alcance social, econômico e legal do uso da informação eticamente e legalmente.

Pode-se dizer que o desenvolvimento das habilidades de conhecer quando há uma necessidade de informação, identificar a informação necessária, encontrá-la, avaliá-la, organizá-la e usá-la efetivamente é sensível ao contexto e ocorre num contínuo de cada indivíduo. Entretanto há incertezas sobre onde estas habilidades serão desenvolvidas. Há correntes que defendem que a biblioteca é o ambiente natural para resolver esses problemas. Outros afirmam que este tema deva se incorporado ao currículo e outros ainda como Behrens (1994) apud (INOUE; NAITO; KOSHIZUKA, 1997) acreditam que para realização dessa tarefa deva-se ampliar a parceria entre educadores e bibliotecários. 
Não há como separar com uma linha divisória explícita quando começa ou termina a atuação do bibliotecário/professor e do professor efetivo de sala de aula no processo de alfabetização informacional. O que se pode dizer é que várias etapas do processo podem ser desenvolvidas na biblioteca e é de suma importância que bibliotecários conheçam como atuar significativamente no contexto educacional. O importante é que sejam abordadas questões de como e por que transformar os espaços de acesso e uso de fontes de informação para proporcionarem inúmeras leituras a serem realizadas entre os mundos das imagens, palavras, hipertextos e hipermídia. Para que as pessoas utilizem a informação transformando suas vidas mais prazerosas, qualitativas e possam atuar amplamente na sociedade.

Habilidades e competências no mundo da alfabetização e letramento são necessárias para saber buscar o conhecimento registrado e organizar informações para facilitar o conviver na Sociedade do Conhecimento. Para isso torna-se relevante conhecer recursos tecnológicos, criar mecanismos para a organização e principalmente evitar a sobrecarga de informação (information overload).

Na Era Digital as pessoas necessitam buscar a atualização constante (upgrades) não só dos recursos tecnológicos, pois determinados softwares são incompatíveis ou perdem a riqueza de seus atributos quando lançados, de sua pertinência, de sua usabilidade. Mas, principalmente a atualização profissional - conhecida também como capacitação continuada, educação permanente ou até mesmo reciclagem. Este termo reciclagem não combina com o enfoque que tratamos da educação do ser humano, por essa razão optamos mencionar a reciclagem somente para objetos (equipamentos e recursos materiais) e jamais para pessoas.

A adaptação constante para sobreviver no mercado competitivo ou principalmente em interagir em nossa sociedade, requer o saber apreender. Na capacitação de pessoas são considerados fatores que estão relacionados entre si: saber utilizar e compreender o porquê da aplicação de determinadas tecnologias; reconhecer as suas características, especificações 
técnicas e usos conforme o perfil da demanda das necessidades dos usuários, saber identificar a relação custo $\mathrm{X}$ benefício de novas práticas ao contexto organizacional.

Ao considerar que tudo se transforma na vida das pessoas, são múltiplas as possibilidades de interação entre o sujeitos, os instrumentos, as técnicas e seus resultados. Nesse ambiente, o ser humano precisa acompanhar o processo de mudança e principalmente estabelecer diretrizes para o desempenho satisfatório de suas funções e atividades.

Esse momento requer a educação do sujeito. Precisa ter autonomia, saber escolher o que seja relevante em sua atuação profissional, e principalmente em exercer a cidadania. Para algumas pessoas tudo pode ser resolvido pelo autodidatismo, para outros são necessárias ações de educação continuada, seja na formação profissional, cultural ou educacional.

Ao serem incorporadas atividades de educação continuada, no cotidiano profissional ou pessoal, torna-se necessário existir mecanismos que facilitem a interação do sujeito bibliotecário com sua relação direta em produtos e serviços de informação. Nesse momento ele é um leitor de páginas de hipermídias e desencadeia o processo de interação pelo vídeo - à distância.

Essa distância pode ser desde o próximo computador ou até mesmo a conexão do outro lado do planeta. A interação pelo vídeo possui características de tempo e espaço distintas, mas quase imperceptíveis. Por exemplo, ao utilizar uma conta de correio eletrônico, às vezes as mensagens localizadas em servidores internacionais como os do Yahoo (http://www.yahoo.com ) ou Gmail (htps://gmail.com ), podem ocupar mais de $100 \mathrm{Mb}$, serem acessadas pelas interfaces gráficas ou programas específicos, ou deixadas para consulta posterior. $\mathrm{Na}$ interação on-line, pelo vídeo, podem ser realizadas operações de leitura, escrita, apagar, enviar ou simplesmente arquivar a mensagem. A cada momento novas possibilidades de interação são disponibilizadas, desde acesso e uso de aplicativos antivírus para arquivos anexados às mensagens; serviços para exclusão direta do Spams (mensagens não solicitadas); agenda virtual; caderneta de endereços, enfim, as facilitações 
da vida moderna disponibilizadas para a interação do sujeito pelo vídeo utilizando teclados, mouse ou comando de voz.

\section{CONSIDERAÇÕES SOBRE A QUALIDADE AMBIENTAL EM BIBLIOTECAS}

A ênfase está em saber cuidar e isto requer: sensibilidade, talento, métodos, técnicas, paciência e perseverança. O saber cuidar no ambiente profissional e pessoal é o elemento fundamental para cultivar as relações pessoais e profissionais dentro de princípios éticos e humanistas, de preservar recursos e principalmente em utilizá-los acertivamente. Envolve fatores de educação, de técnicas e práticas para balancear aspectos do espaço (onde), tempo (quando), custos (quanto), velocidade de transmissão (como) e resultados alcançados (para quem e o que). Consiste no fortalecimento do humano nas relações pois este está na essência da sociedade: tecer uma grande teia na rede de relações e de interesses.

Quanto ao uso de métodos, de técnicas e de instrumentos também são necessários cuidados. Cada aspecto necessita de atenção, presteza e eficácia sem perder a elegância e a boa educação do bibliotecário, pois além de administrar e organizar ambientes para dinamizar o acesso aos acervos e estimular a leitura, trata-se de um educador. Educador no amplo sentido da palavra, instrui o espírito, a inteligência e o coração (pelo amor). Precisa ter o talento em saber lidar com pessoas e com as máquinas. Em saber como facilitar o acesso à informação, saber estimular uma boa leitura, interagir com o leitor para entender os seus desejos, oferecer novas oportunidades para ampliar o uso da informação, gerar espaços para discussão da literatura seja ela técnica, de lazer ou científica para ser um facilitador do processo da geração e do uso do conhecimento.

A orientação no acesso e no uso da informação é uma constante do cotidiano bibliotecário. E com as hipermídias digitais cabe ao bibliotecário preparar o ambiente para a recepção da informação, isto é, vai desde verificar os requisitos técnicos e operacionais, como a escolha e upgrade de softwares para assistir uma apresentação numa câmera web até mesmo verificar as condições de áudio e vídeo para adequar conforme o público. Significa saber 
escolher equipamentos conforme critérios específicos para atender qualitativamente as pessoas que irão utilizar estes espaços.

Existem muitos transtornos para deixar o ambiente ideal. Ao bibliotecário compete minimizar os conflitos técnicos e operacionais que acontecem para que os efeitos dos impactos da divisão digital não venham a dificultar mais ainda o acesso e uso da informação. Facilitar o acesso e estimular o uso de fontes de informação, são as bases para o desenvolvimento e a construção da Sociedade do Conhecimento.

O bibliotecário precisa saber organizar e administrar ambientes adequados para estudos, encontros intelectuais, debates com autores e discussões de leituras primordiais para o transmitir, gerar e inovar conhecimentos nas diferentes áreas do saber. Para isso é importante que ele entenda as transições pelas quais passa o leitor e identifique as necessidades e demandas desse leitor de páginas ao indivíduo que interage pelo vídeo: o leitor de telas na teia (world wide web).

$\mathrm{Na}$ biblioteca as atividades precisam ser coordenadas e avaliadas pelos bibliotecários para atender qualitativamente as pessoas. O planejamento dos serviços e produtos a serem oferecidos pela biblioteca precisam estar centrados nos usuários e seus processos vivenciais de busca e uso de informações conforme as necessidades apresentadas no cotidiano.

A tendência de atender o leitor real (presente fisicamente na biblioteca) e o leitor virtual (que interage pelo vídeo), satisfatoriamente, consistem em ofertar recursos informacionais presenciais e on-line, isso requer um diagnóstico do contexto e das demandas dos leitores para desenvolver ações no sentido de propiciar desde facilidades de acesso aos usuários; a digitalização de material; participar na educação continuada das pessoas; gerenciar o uso de licenças de softwares; dinamizar o acesso aos portais do governo eletrônico (e-gov) e estabelecer a arquitetura de sistemas para a biblioteca participar ativamente na grande teia mundial com vistas de minimizar a divisão digital. 
Quanto aos recursos informacionais, o bibliotecário precisa saber trabalhar com o computador na rede mundial, e utilizá-lo como uma ferramenta do cotidiano. Para isso precisa conhecer quais os tipos de recursos que poderão ser utilizados no computador; como colocar esse computador plugado na Internet; quais seriam as mudanças mais drásticas na infra-estrutura operacional. Algumas respostas podem ser vistas nos estudos na área de automação de bibliotecas ao longo das últimas duas décadas e apontam para a série de mudanças sejam nos processos, nos produtos e nos serviços ofertados pelas bibliotecas. A outra grande mudança perceptível é a autonomia (empowerment) do leitor. Este ser humano, detentor de sua autonomia, para qual são direcionados a maioria dos serviços e produtos da biblioteca.

O bibliotecário necessita estar presente na tomada de decisões e no estabelecimento das políticas de acesso e de uso de fontes de informação on-line, pois é a pessoa que está em contato direto com o usuário, tendo uma maior percepção de suas necessidades.

No manuseio das fontes de informação é preciso acompanhar as mudanças dos formatos (suportes), dos tipos de documentos disponíveis e acessíveis. A interação do leitor acontece nas relações diretas e indiretas. Cabe prestar atenção ao comportamento e ao processo cognitivo do leitor para desenvolver espaços mais interativos, simples e com amplos recursos de linguagens (visual, textual, não-verbal) .

A administração de fontes digitais on-line perpassa caminhos similares aos processos vivenciados na administração de fontes tradicionais no que tange ao estímulo e promoção de leituras.

O grande salto educacional no que se refere ao uso acertivo das informações para a construção de conhecimento ainda está em construção. O bibliotecário necessita estar atento para criar ambientes diferenciados e cuidadosos, esteticamente agradáveis, tecnicamente precisos e confiáveis, estejam eles no âmbito da concretude e ou da virtualidade. O importante é que eles favoreçam aos leitores o livre trânsito entre leituras impressas, digitais e virtuais. Os meios de acesso aos conteúdos informacionais não podem 
ser entraves e sim, funcionar como molas propulsoras para o desencadeamento de aprendizagens.

\section{REFERÊNCIAS}

ARMS , W. Y. Automated digital libraries: how effectively can computers be used for the skilled tasks of professional librarianship? D-Lib Magazine, v. 6, n. 7/8, Jul./Aug. 2000

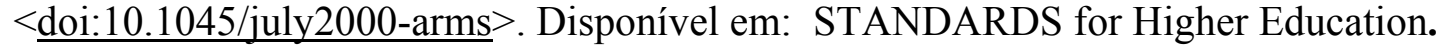
Disponível em: $<$ http://www.ala.org/ala/acrl/acrlstandards/standards.pdf $>$. Acesso em: 03 maio 2004.

BEHRENS, S. J. A conceptual analysis and historical overview of information literacy. College \& Research Libraries, v. 55, n. 4, p. 318, 1994.

BLATTMANN, U.; FRAGOSO, G. M. O Zapear a informação em bibliotecas e na Internet. Belo Horizonte: Autêntica, 2003. 103 p. ISBN 8575260766

BOFF, L. Saber cuidar: ética do humano - compaixão pela terra. Petrópolis: Vozes, 1999. 199 p. ISBN 85.326.2162-7

BRASIL. Ministério do Trabalho e Emprego. Classificação Brasileira de Ocupações CBO. Edição 2002. Disponível em:

$<$ http://www.mtecbo.gov.br/busca/descricao.asp?codigo=2612>.

CARBO, T. Mediacy: knowledge and skills to navigate the information highway. Intl. Inform \& Libr. Rev., n. 29, p. 393-401, 1997.

DELORS, J. et al. Educação: um tesouro a descobrir: relatório para a UNESCO da Comissão Internacional sobre Educação para o século XXI. 4. ed. São Paulo:

Cortez; Brasília, DF : MEC : UNESCO, 2000.

HORTON, F. W. Jr. Information literacy vs computer literacy. American Society for Information Science Bulletin, v. 9, n. 4, p.14-16, 1983.

HUMMELSHOJ, M. Virtual Reference Services in Public Libraries From "Access to" to “Use of" Information . In: Annual digital reference conference, 4, 2002. Chicago, IL. Anais eletrônicos... Disponível em:

$<$ http://www.vrd.org/conferences/VRD2002/proceedings/hummelshojpaper.shtml> 
INOUE, H.; NAITO, E.; KOSHIZUKA, M. Mediacy: what it is? Where to go? Intl. Inform \& Libr. Rev., n. 29, p. 403-413, 1997.

KASKE, N., ARNOLD, J. An unobtrusive evaluation of online real time library reference services. Library Research Round Table, American Library Association Annual Conference, Atlanta, GA, June 15, 2002 Disponível em:

$<$ http://www.lib.umd.edu/groups/digref/LRRT.html $>$.

McGARRY, K. Definitions and meanings of literacy. In: BARKER; LONSDALE (Eds.). Skills for life: the value and meaning of literacy. London: Taylor Graham, 1994.

MORIN. E. Os sete saberes necessários à educação do futuro. São Paulo: Cortez; Brasília, DF: UNESCO, 2000.

SALES, M. B. de; CYBIS, W. de A. CHECKLIST para avaliação de acessibilidade de interfaces web para usuários idosos. In: Seminário ATIID - acessibilidade, TI e inclusão digital, 2003, São Paulo. Anais eletrônicos... Disponível em:

$<$ http://hygeia.fsp.usp.br/acessibilidade/cd/atiid2003/artigos/53checklist.doc $>$.

SOARES, Magda. Alfabetização e letramento. São Paulo: Contexto, 2003. 128 p.

1998. $125 \mathrm{p}$.

. Letramento: um tema em três gêneros. 2. ed Belo Horizonte: Autêntica,

MAROUVA FALLGATTER FAQUETI

Bibliotecária - Biblioteca Setorial do Colégio Agrícola de Camboriú - Universidade Federal de Santa Catarina

E-mail: marouva@bu.ufsc.br

URSULA BLATTMANN

Professora Departamento de Ciência da Informação - Universidade Federal de Santa Catarina 89000-000 Florianópolis Santa Catarina

E-mail: ursula@ced.ufsc.br

Artigo aceito para publicação em: 01/06/2004

(C) Revista Digital de Biblioteconomia e Ciência da Informação,Campinas, v. 2, n. 1, p . 57-70, jul./dez. 2004-ISSN: 1678-765X. 